\title{
PENGGUNAAN KAEDAH "RAWATAN JARAK JAUH" DALAM RAWATAN PENYAKIT DI PUSAT RAWATAN ISLAM DI MALAYSIA: SATU ANALISIS HUKUM
}

\section{The Method of "Long Distance Treatment" in Islamic Treatment Centres in Malaysia: An Analysis from Islamic Law Perspective}

\author{
Khadher Ahmad * \\ Rushdi Ramli **
}

\begin{abstract}
Long distance treatment is one of the methods conducted at the Islamic Treatment Centres in Malaysia. Through this method of treatment, the practitioners are not in the situation of being face-to-face with their patients. In contrast, the treatment will be carried out by using certain approaches and skills without the attendance of the patients'. Therefore, there will be some sorts of doubt and uncertainty in their way of treatment since it will be carried out without any face-to-face meeting with the patients. The question is, to what extent is this way of treatment allowed in Islam? Hence, this article seeks to analyse the views of Muslim scholars pertaining to this method of treating disease. Through field studies conducted at 23 Islamic Treatment Centres throughout Malaysia, data pertaining to the use of the long distance treatment were collected. Data collection was based on interviews and direct observation. The study found that there is only one hadith which can be relied upon concerning the usage of long distance treatment. Basically this method of treatment was allowed by the Prophet SAW. In overall, from the Islamic
\end{abstract}

* FELO/SLAI di Jabatan al-Quran \& al-Hadis, Akademi Pengajian Islam, Universiti Malaya.

** Pensyarah, Jabatan Fiqh \& Usul, Akademi Pengajian Islam, Universiti Malaya. 
perspective, the practice of this treatment can be divided into two different views; first: it is permissible but should be based on certain conditions, and second, the method is prohibited.

Keywords: Islamic Medical Treatment, Long Distance Treatment, Disease Treatment, Malaysia

\section{PENDAHULUAN}

Dewasa kini menyaksikan perkembangan dan pertumbuhan pesat pusat-pusat rawatan penyakit yang bertunjangkan kepada rawatan Islam. Segelintir pusat rawatan menjadikan title "rawatan Islam" untuk menarik minat masyarakat dan tidak dinafikan sebahagian pusat rawatan Islam yang lain benar-benar menjadikan syariat Islam sebagai landasan utama dalam khidmat rawatan penyakit yang dijalankan.

Isu utama dalam rawatan Islam adalah dari sudut kesahihan dan keharusan sesuatu kaedah rawatan yang dipraktikkan sama ada di atas landasan syariat atau menyalahinya. Bahkan, sebahagian kaedah yang dipraktikkan di pusat-pusat rawatan Islam tersebut meragukan sehingga boleh menimbulkan fitnah terhadap rawatan Islam yang sebenar.

Kaedah rawatan jarak jauh adalah di antara kepelbagaian kaedah rawatan yang dipraktikkan di pusat-pusat rawatan Islam di Malaysia. Realitinya dapat dilihat pada hari ini apabila sebahagian pusat rawatan Islam mengiklankan kepada masyarakat khidmat rawatan tersebut bagi menarik perhatian mereka. Dari itu, persoalannya, adakah kaedah rawatan tersebut dibenarkan dalam Islam atau ia bercanggah dengan syariat Islam dan menyamai amalan para bomoh yang menyimpang? Oleh yang demikian, artikel ini menjelaskan dengan lebih terperinci tentang hukum pengamalan kaedah rawatan jarak jauh dalam rawatan penyakit. Di akhir artikel ini, diharapkan ia dapat dijadikan panduan utama dalam rawatan penyakit khususnya kepada perawat dan pesakit dan umumnya kepada semua anggota masyarakat. 


\section{SKOP DAN METODOLOGI}

Kajian awal telah dijalankan di 23 pusat rawatan Islam yang terpilih. Data-data dikumpulkan melalui metode temubual dan pemerhatian terhadap kaedah dan pendekatan yang dijalankan di pusat-pusat rawatan Islam tersebut. Hasil kajian tersebut terdapat 20 kaedah dan pendekatan yang dilakukan di pusat-pusat rawatan Islam dalam rawatan penyakit. Antaranya kaedah ruqyah, kaedah pukulan, kaedah rawatan jarak jauh, kaedah scanning atau diagnos dan lain-lain lagi. Keseluruhan kaedah dan pendekatan diteliti dan dianalisis berdasarkan nas al-Quran dan Sunnah serta pandangan ulama.

Dalam artikel ini, penulis tidak akan menghuraikan keseluruhan kaedah dan pendekatan rawatan yang dilakukan di pusat-pusat rawatan Islam tersebut. Fokus utama adalah melihat kepada salah satu daripada pendekatan itu iaitu menganalisis dan menilai hukum serta pandangan para ulama berhubung dengan kaedah rawatan jarak jauh. Dari sudut pelaksanaannya, terdapat golongan yang menolak menggunakan kaedah ini atas alasan tiada nas yang membenarkannya atau ia meragukan. Namun, terdapat sebahagian golongan lain yang tidak menolak penggunaan kaedah rawatan ini dalam rawatan penyakit sehingga diletakkan ia sebagai salah satu daripada kaedah rawatan Islam yang dibenarkan.

\section{HASIL KAJIAN}

Hasil penelitian terhadap 23 pusat rawatan Islam di Malaysia yang telah dipilih, kaedah rawatan jarak jauh adalah merupakan kaedah yang mendapat tempat dalam kalangan perawat di pusat-pusat rawatan Islam tersebut. ${ }^{1}$ Walaupun begitu, tidak semua pusat rawatan Islam mengamalkan kaedah ini. Lihat jadual 1 di bawah

\footnotetext{
Kajian telah dilakukan oleh pengkaji selama tiga tahun untuk meneliti kaedah-kaedah rawatan yang dipraktikkan di pusat-pusat rawatan Islam di Malaysia yang dipilih sebagai sample kajian. Lihat Khadher Ahmad (2012), "Analisis Hadith-hadith Mengenai Rawatan Sihir Dalam Al-Kutub Al-Sittah: Aplikasi Di Pusat Rawatan Islam Di Malaysia" (Tesis Ijazah Doktor Falsafah, Jabatan al-Quran dan al-Hadith, Akademi Pengajian Islam, Universiti Malaya, Kuala Lumpur).
} 
berhubung dengan penggunaan kaedah rawatan jarak jauh dalam rawatan penyakit.

Jadual 1: Pusat rawatan Islam yang mengamalkan kaedah rawatan jarak jauh dalam rawatan penyakit

\begin{tabular}{|c|c|c|c|c|c|c|c|c|c|c|c|c|}
\hline $\begin{array}{c}\text { Pendekatan } \\
\text { dan Kaedah } \\
\text { Rawatan / } \\
\text { Nama Pusat } \\
\text { Rawatan }\end{array}$ & 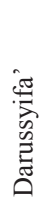 & 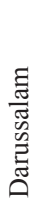 & $\frac{\sum}{2}$ & $\begin{array}{l}\frac{1}{2} \\
\frac{2}{2} \\
\frac{1}{4}\end{array}$ & 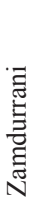 & 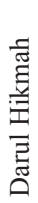 & 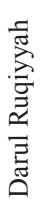 & 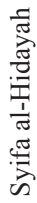 & 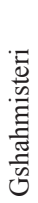 & 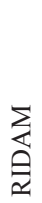 & 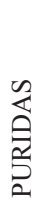 & $\frac{\varangle}{a}$ \\
\hline $\begin{array}{c}\text { Kaedah } \\
\text { Rawatan Jarak } \\
\text { Jauh } \\
\end{array}$ & & & & / & & & & & & / & / & 1 \\
\hline $\begin{array}{c}\text { Pendekatan } \\
\text { dan Kaedah } \\
\text { Rawatan / } \\
\text { Nama Pusat } \\
\text { Rawatan }\end{array}$ & 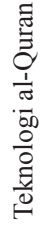 & 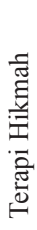 & $\begin{array}{l}\overline{0} \\
\stackrel{0}{E} \\
0 \\
n\end{array}$ & $\underset{⿱ ㇒}{\leftrightarrows}$ & 竝 & 离 & 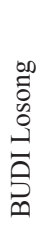 & 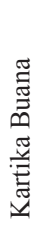 & 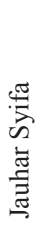 & 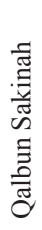 & 昙 & \\
\hline $\begin{array}{c}\text { Kaedah } \\
\text { Rawatan Jarak } \\
\text { Jauh }\end{array}$ & I & & & & & & & & & & / & \\
\hline
\end{tabular}

Berdasarkan jadual di atas, hanya lima pusat rawatan Islam sahaja yang mengakui bahawa mereka mengaplikasikan kaedah rawatan jarak jauh dalam rawatan penyakit iaitu Pusat Rawatan Islam Darul Manzil (RIDAM), ${ }^{2}$ Pusat Rawatan Ikhtiar Darul

2 Rawatan Islam Darul Manzil (RIDAM) telah ditubuhkan oleh Khairul Syakirin bin Abdul Wahab secara tidak rasmi pada tahun 1997 yang beroperasi di kediaman pengasasnya sendiri yang beralamat di Lot 2867, Taman Jakar, 24000 Kemaman, Terengganu. Setelah itu, pusat rawatan ini secara rasminya berdaftar dengan Suruhanjaya Syarikat Malaysia dibawah nama Manzil Enterprise pada 4 Januari 2008. Melalui kunjungan pengkaji ke pusat rawatan ini, ia telah berpindah ke alamat No.16, PT5982, Taman Intan, Geliga Besar, 24000 Kemaman, Terengganu. 
Penggunaan Kaedah "Rawatan Jarak Jauh" Dalam Rawatan Penyakit di Pusat Rawatan Islam di Malaysia: Satu Analisis Hukum

Syifa' (PURIDAS), ${ }^{3}$ Pusat Rawatan Islam al-Madani (PRIA), Pusat Rawatan Pancaran Sinar Nur (Sinar Nur) ${ }^{4}$ dan Pusat Rawatan Teknologi al-Quran dan Asma al-Husna. ${ }^{5}$

\section{RAWATAN JARAK JAUH}

Kaedah rawatan jarak jauh adalah merujuk kepada kaedah rawatan yang dilakukan untuk merawat pelbagai penyakit tanpa kehadiran pesakit ${ }^{6}$ atau merawat rumah dan bangunan tanpa kehadiran perawat ke tempat tersebut. Rawatan jarak jauh ini boleh berlaku dalam banyak keadaan, tetapi pada kebiasaannya rawatan dijalankan tanpa perawat melihat pesakit atau pergi ke sesuatu tempat.

3 Pusat Rawatan Ikhtiar Darul Syifa' (PURIDAS) telah ditubuhkan oleh Hj. Uzip @ Othman B. Mohd pada tahun 1992 dan beroperasi di kediaman pengasasnya sendiri di alamat B99, Kampung Kubang Durian, 20050 Gelugur Kedai, Kuala Terengganu, Terengganu Darul Iman, berhampiran dengan Masjid Gelugur Kedai.

4 Pusat Rawatan Pancaran Sinar Nur telah ditubuhkan oleh Dr. Mohd Zaid Mohamad pada tahun 2008 Namun demikian, Dr. Mohd Zaid telah terlibat dalam menyediakan khidmat rawatan sudah hampir 10 tahun yang lalu. Pusat rawatan ini beroperasi sepenuh masa yang dikendalikan oleh Dr. Mohd Zaid bersama dengan isteri beliau dan tidak mempunyai ahli khusus melainkan ia beroperasi seperti sebuah klinik persendirian. Melalui kunjungan pengkaji ke pusat rawatan ini yang beralamat di Lot 8133 C, Tingkat Bawah, Jalan Gong Badak, 21300 Kuala Terengganu, Terengganu, didapati bahawa pusat rawatan beroperasi di premis atau bangunan dua tingkat yang khusus. Ruang premis tersebut telah disediakan ruang khusus untuk menjalankan rawatan, kuanter perkhidmatan, ruang menunggu, stor barang dan ruang pameran dan jualan produk-produk kesihatan.

5 Pusat Rawatan Teknologi al-Quran dan Asma al-Husna telah ditubuhkan oleh Ahmad Suhaimi bin Abu Samah al-Hafiz pada lebih kurang 10 tahun yang lepas apabila dilancarkan laman web khusus untuk pusat rawatan ini yang diberi nama penawar.com. Pusat rawatan ini pada awalnya beroperasi di kediaman pengasasnya sendiri di alamat No. 15 Jalan Bahagia 28, Taman Intan, 28000, Temerloh, Pahang. Namun, telah berpindah ke alamat PT4491 Jalan Rumpun Makmur (Depan Pasar Mini KPR), 28050 Kuala Krau, Pahang pada tahun 2009.

$6 \quad$ Khadher Ahmad (2012), op.cit., h. 291. 
Antara pendekatan dalam rawatan jarak jauh adalah rawatan yang dijalankan melalui penggunaan alatan perhubungan seperti telefon, internet dan lain-lain. Hal ini bermakna, rawatan yang dilakukan oleh perawat adalah melalui percakapan dalam telefon di mana perawat dan pesakit tidak bersemuka, tetapi mereka berkomunikasi ketika itu antara satu sama lain walaupun jarak antara mereka beribu batu. Dalam keadaan lain, perawat juga merawat pesakit dengan menggunakan gambar pesakityang dibawa oleh keluarga pesakit. Hal ini disebabkan oleh keengganan pesakit untuk datang mendapatkan rawatan. Ini bermakna, perawat akan membacakan ruqyah ke atas pesakit yang berada di dalam gambar tersebut. ${ }^{7}$ Bagi merawat rumah yang diganggu oleh makhluk halus atau membantu memagar kawasan rumah, kaedah ini juga dilakukan di mana tuan rumah hanya perlu menyatakan alamat dan memberi sedikit gambaran rumah bagi proses pemagaran dan perlindungan rumah yang dilakukan oleh perawat tanpa kehadiran perawat ke kediaman berkenaan.

Manakala dalam rawatan menggunakan alat perhubungan seperti telefon berlaku komunikasi antara pesakit dan perawat cuma tidak bersemuka. Rawatan dilakukan dengan perawat meminta agar pesakit menyediakan bahan rawatan seperti air mineral dan lain-lain lalu melalui alat tersebut perawat membacakan ruqyah dan diperdengarkan juga ke atas bahan rawatan tadi. Dalam keadaan tertentu, jika terdapat tindak balas daripada pesakit seperti mengerang kesakitan atau kepanasan, dapat menunjukkan bahawa kaedah tersebut memberi kesan dalam rawatan yang dijalankan.

Kemudian, dalam rawatan terhadap kediaman atau bangunan atau premis tertentu, berdasarkan pemerhatian pengkaji, terdapat perawat yang meminta agar pesakit melakarkan pelan rumahnya atau premisnya dan perawat akan membantu mengesan kehadiran makhluk halus dalam premis atau kediaman tersebut. Selepas

7 Selalunya keadaan ini disebabkan oleh pesakit yang disihir akan dihalang oleh jin sihir yang menguasai dirinya daripada mendapatkan rawatan atau dalam keadaan lain, pesakit itu terlalu uzur dan sukar untuk bergerak disebabkan oleh perbuatan sihir. Dalam keadaan lain, terdapat juga pesakit yang tidak sedar bahawa dirinya disihir, tetapi melalui pemerhatian pasangannya dan tanda-tanda yang diperoleh, pesakit itu sebenarnya terkena sihir. Jadi, pasangannya membantu mendapatkan rawatan dengan membawa gambar pesakit tersebut. 
itu, perawat akan membacakan ayat-ayat ruqyah tertentu dan melakukan isyarat memagar kawasan sekeliling rumah atau kediaman tersebut dan pada masa yang sama menghalau keluar makhluk halus yang mendiami kawasan itu. ${ }^{8}$

Selain itu, terdapat juga rawatan jarak jauh yang dilakukan dengan keadaan rawatan secara ghaib iaitu perawat atau pengamal perubatan tersebut menyarankan pesakit agar melaksanakan segala arahan yang perlu dilakukan. Lalu pada sebelah malam nanti akan datang perawat (dalam keadaan ghaib atau tidak diketahui oleh perawat) untuk membantu pesakit tersebut menyembuhkan penyakitnya. Selalunya amalan ini dilakukan oleh para bomoh.

Dalam penelitian pengkaji di pusat-pusat rawatan Islam, kaedah rawatan jarak jauh diamalkan di pusat-pusat rawatan Islam seperti Pancaran Sinar Nur, Pusat Rawatan Islam Darul Manzil (RIDAM), Terapi Darul Hikmah, PURIDAS dan AKRINE.9 Bahkan, Darussyifa' $^{10}$ juga menggunakan kaedah rawatan jarak jauh ini berdasarkan keadaan dan keperluan terhadap rawatan tersebut. Hal ini kerana, Darussyifa' melalui pengasasnya Dr. Haron Din berusaha untuk mengelakkan daripada menggunakan teknik atau kaedah yang meragukan dan menimbulkan salah faham dalam masyarakat. Manakala bagi AKRINE, kaedah rawatan jarak jauh sering dilakukan dalam proses pemagaran rumah sahaja.

$8 \quad$ Pemerhatian pengkaji terhadap rawatan yang dilakukan oleh salah seorang perawat daripada AKRINE yang melakukan rawatan mengesan makhluk halus di kediaman rumah dan membantu memagar kawasan rumah tersebut.

9 Akademi Rawatan Islam Nur Ehsan (AKRINE) ditubuhkan oleh Ustaz Abdul Majid Hasan pada tahun 2005 yang beroperasi di sebuah bangunan yang dibina khusus bersebelahan dengan kediaman Ustaz Abdul Majid di alamat Lot 2984, Lorong Beringin, Kuang, Selangor.

10 DARUSSYIFA' telah diasaskan oleh Dato' Dr. Haron Din melalui penubuhan Persatuan Kebajikan dan Pengubatan Islam Malaysia atau singkatannya Darussyifa' pada 17 April 1988. Ia beroperasi dibangunan rasmi di alamat No.5, Jalan 1/7D, 43650 Bandar Baru Bangi, Selangor bermula pada 17 Mac 1991 bersamaan 1 Ramadan $1411 \mathrm{H}$ hingga sekarang yang menyediakan khidmat rawatan penyakit kepada masyarakat awam dan pembelajaran ilmu pengubatan Islam, bagi ahlinya. 


\section{DALIL TERHADAP KEHARUSAN MENGGUNAKAN KAEDAH RAWATAN JARAK JAUH}

Berhubung dengan pengamalan kaedah rawatan jarak jauh ini, adakah ia dibenarkan atau ia menyalahi tuntutan syarak? Dalam menjawab persoalan ini, Dr. Haron Din mengatakan bahawa kaedah rawatan jarak jauh adalah salah satu daripada kaedah yang baik dalam rawatan penyakit. Kaedah ini dipetik dan difahami daripada sebuah hadith Nabi SAW yang menyarankan agar seseorang itu mendoakan sahabatnya tanpa diketahui oleh sahabatnya itu. Ia juga termasuk dalam konteks doa yang mendapat perkenan Allah SWT kemakbulannya. ${ }^{11}$

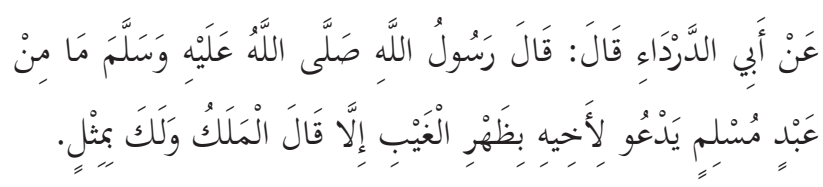

Maksudnya: "Tidak ada seorang hamba Muslim yang mendoakan kebaikan untuk saudaranya di belakangnya (tanpa diketahui oleh saudaranya itu) melainkan terdapatnya Malaikat yang akan berkata: Bagi engkau segala kebaikan yang engkau doakan untuknya." 12

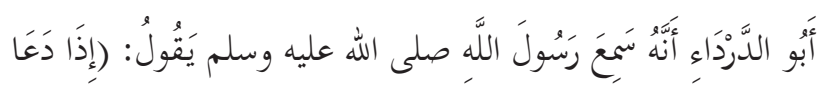

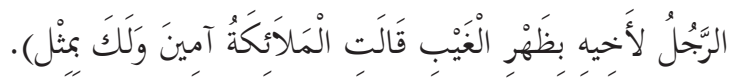

Maksudnya: "Apabila seseorang lelaki mendoakan (kebaikan) bagi saudaranya di belakangnya (tanpa diketahui oleh suadaranya itu), maka Malaikat akan

\footnotetext{
11 Tembual bersama dengan Dr. Haron Din di kediaman beliau pada 13 Jun 2011 jam 8.30 pagi.

12 Hadith riwayat Muslim, Kitāb al-Dhikr wa al-Du'ā' wa al-Tawbah wa al-Istighfār, (بَاب فَضْل الدُعَعَاء للْمُسْمينَ بظَهْر الْغَيْبَ), no. hadith 6927. Lihat Muslim bin al-Hájjāj Abú Ḥusán al-Qushayrī al-Naysābūrī (2000), Șaḥịh Muslim dalam Mawsū'ah al-Hadìth al-Sharīf al-Kutub alSittah, al-Riyāẹ: Dār al-Salam li al-Nashr wa al-Tawzī', h. 1152.
} 
mengucapkan amin dan mendoakan ke atas dirinya doa seperti itu. "13

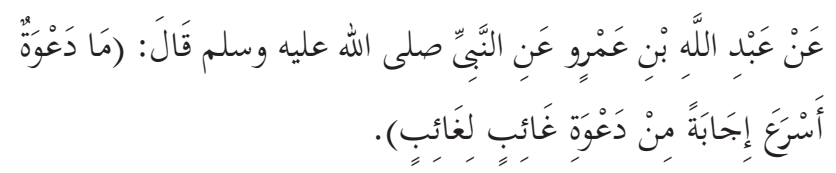

Maksudnya: "Tiadalah doayang segera dimakbulkan (oleh Allah) daripada doa seorang Muslim kepada seorang Muslim yang lain yang tidak bersama dengan dirinya." 14

Apa yang dinyatakan oleh Dr. Haron Din adalah merujuk kepada kaedah rawatan jarak jauh yang menekankan kepada penggunaan ruqyah-ruqyah al-shar'iyyah yang bukan menggunakan jampi serapah dan bukan mendakwa bahawa akan datang suatu makhluk pada malam hari untuk membantu merawatnya. Rawatan tersebut masih dalam bentuk rawatan yang mematuhi tuntutan syariat Islam.

Dalam 'Awn al-Ma'būd yang memetik pendapat al-Ṭibbī berkata bahawa sebahagian daripada golongan salaf apabila mahu mendoakan sesuatu ke atas dirinya, maka didoakan ke atas saudaranya dengan doa tersebut agar dapat didoakan oleh malaikat seperti doa tersebut. Bahkan doa tersebut lebih mudah

13 Hadith riwayat Abū Dāwūd, Kitāb al-Witr, (باب الدُعَاء بظَهْر الْغَيْب), no. hadith 1534. Lihat Abū Dāwūd, Sulaymān bin ál-Ash' ‘́á al-Sajastānī al-Azdī (2000), Sunan Abī Dāwūd, dalam ibid., h. 1336.

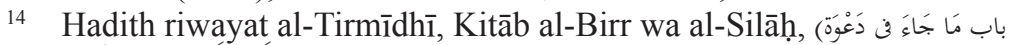
(الأَخ لأَخيه بظَهْر الْنَيْب 1980 dan Abū Dāwūd, Ko. Kitāb al-Witr,

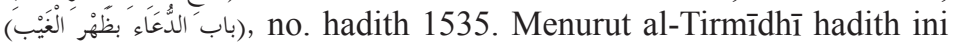
hadith gharīb tidak diketahui melainkan melalui wajah (riwayat) ini sahaja. Lihat Tirmīdhī, Abū 'Īsā Muhammad bin 'Īsā (2000), Jāmi' al-Tirmìdhī, dalam ibid., h. 1850 dan Abū Dawūd (2000), ibid., h. 1336. 
dimakbulkan Allah SWT. ${ }^{15}$ Hal yang sama juga disebutkan oleh al-Nawawī dalam al-Minhāj. ${ }^{16}$

Al-Nawawī dalam al-Minhāj berkata bahawa maksud berdoa dibelakangnya adalah merujuk kepada berdoa secara rahsia tanpa diketahui bahawa seseorang itu telah didoakan oleh sahabatnya. Tambahan lagi, ia lebih mengundang rasa keikhlasan ${ }^{17}$ dalam berdoa berbanding berdoa dihadapannya. Manakala al-Qāḍ̄ berkata bahawa pada hadis ini menunjukkan kelebihan berdoa secara rahsia ke atas saudara Muslim yang lain sekalipun doa itu ditujukan ke atas satu kumpulan orang Islam maka ia termasuk dalam erti kata berdoa sedemikian. ${ }^{18}$

Oleh yang demikian daripada hadis dapat dikaitkan bahawa seseorang perawat yang membantu saudaranya Muslim yang sakit dengan memanjatkan doa atau melalui perlaksanaan ibadah seperti solat hajat dan sebagainya, maka ia termasuk dalam erti kata membantu merawat pesakit itu secara jarak jauh tanpa diketahui oleh pesakit. Maka dengan izin dan perkenan Allah SWT, pasti akan disembuhkan oleh Allah SWT.

\section{PENJELASAN HUKUM TERHADAP KAEDAH RAWATAN JARAK JAUH}

Berhubung dengan kaedah rawatan jarak jauh, didapati bahawa kaedah ini juga berkesan dalam merawat pesakit khususnya dalam membantu pesakit yang enggan mendapatkan rawatan, menghadapi keuzuran atau jarak rumahnya yang jauh. Ini kerana pendekatan ini masih menggunakan kaedah ruqyah al-shar'iyyah, cuma ia dilakukan tanpa kehadiran pesakit sahaja. Dalam keadaan yang lain, ahli keluarga membawa gambar pesakit lalu bertemu dengan

\footnotetext{
15 'Aẓ̄̄m Abādī, al-'Allāmah Abū al-Ṭayyib Muhammad Shams al-Dīn al-Haq (1969M/1388H), 'Awn al-Ma 'būd Sharh Sunan Abī Dāwūd. ditahqiqkan oleh 'Abd al-Rahmān Muhammad 'Uthmān, al-Madīnah al-Munawwarah: al-Maktabah al-Salafiyyah, j. 4, h. 394.

16 Abū Zakariyyā Yahyā bin Sharīf bin Muriy al-Nawawī, (1392H), al-Minhāj Sharh Șah̄ịh Muslim bin al-Hajjāj. Bayrūt: Dār Ihyyā' alTurāth al-'Arabī, j. 17, h. 49.

17 Ibid.

18 Ibid.
} 
perawat untuk mendapatkan rawatan di samping menyatakan nama pesakit dan masalah yang dihadapi.

Berkaitan dengan penggunaan kaedah rawatan jarak jauh dalam rawatan penyakit, pengkaji dapat membahagikan kepada dua pandangan yang utama dari sudut keharusan dan pengharaman penggunaan kaedah ini.

Pertama: Diharuskan untuk menggunakan kaedah jarak jauh jika terdapat keuzuran dan kepayahan dari sudut keengganan pesakit atau mangsa untuk datang mendapatkan rawatan akibat daripada masalah dan penyakit yang dihadapi seperti masalah gangguan, terkena sihir sehingga menyukarkan pergerakan atau boleh mendatangkan kecederaan jika bersama dengan orang ramai dan lain-lain lagi. ${ }^{19}$ Selain itu, diharuskan juga menggunakan kaedah ini dalam situasi ia dilakukan dalam keadaan langsung di mana perawat dan pesakit saling berhubung dan saling mendengar antara satu sama lain melalui penggunaan alat telekomunikasi seperti telefon rumah atau bimbit. Ini bermakna semasa rawatan sedang dilakukan wujud perhubungan langsung antara pesakit dan perawat serta ia dilakukan dalam keadaan kedua-dua pihak sedar. Walaupun begitu, dari sudut pelaksanaan kaedah ini, perawat perlu menggunakan kaedah ruqyah al-shar iyyah dan menggunakan bahan rawatan yang dibenarkan serta menghindari daripada menggunakan jampi yang mengandungi unsur syirik dan pemujaan kepada selain Allah serta bahan-bahan yang diharamkan seperti najis, benda-benda yang kotor, busuk, menjijikkan dan sebagainya lagi.

Dalam situasi yang lain pula, juga termasuk dalam rawatan jarak jauh adalah melalui amalan solat hajat dan mendoakan kesembuhan bagi pesakit. Melalui amalan ini, ia adalah diharuskan, bahkan Nabi SAW sangat menggalakkan seseorang Muslim itu

19 Ini bermakna, dari kalangan ahli keluarga membawa gambar dan menjelaskan maklumat peribadi pesakit serta masalah sihir yang dihadapi kepada perawat dan seterusnya perawat melalukan rawatan melalui penggunaan kaedah ruqyah al-shar iyyah dan bahan-bahan yang sesuai untuk penyakit yang dihadapi. Maka atas nasihat perawat, ahli keluarga akan membantu untuk merawat pesakit tersebut. Jika tidak disertakan gambar, memadai dengan menyatakan nama pesakit sahaja. 
mendoakan kesejahteraan bagi Muslim yang lain dan adalah lebih berkesan jika doa yang dipanjatkan tersebut tidak diketahui oleh sahabat yang didoakan tersebut melainkan Allah SWT sahaja.

Kedua: Diharamkan menggunakan kaedah rawatan jarak jauh sekiranya tidak melibatkan sebarang perhubungan secara langsung antara perawat dan pesakit atau menggunakan perantaraan makhluk halus. Contohnya perawat menyatakan bahawa beliau akan menjalankan rawatan (iaitu selepas mendapatkan maklumat dan persetujuan dari pesakit atau ahli keluarga) apabila tibanya waktu malam, pesakit akan didatangi seseorang yang tidak dikenali ketika tidur (dalam keadaan tidak sedar) untuk merawat pesakit tersebut. Pesakit juga disyaratkan untuk meletakkan bahan-bahan tertentu yang diberikan oleh perawat di bawah bantal tidurnya dengan tujuan rawatan sedemikian.

Cara rawatan sedemikian jelas mengaitkan dengan pertolongan makhluk ghaib yang tidak dapat dilihat dengan mata kasar. Bahkan, ia menyerupai amalan perbomohan yang mendakwa bahawa akan ada makhluk yang akan membantu merawat pesakit tersebut ketika tidur seperti akan didatangi oleh makhluk berjubah putih dan berserban atau mendakwa bahawa akan didatangi oleh seorang syeikh yang datang merawat pesakit itu dan pelbagai keadaan lagi. Secara umumnya cara rawatan sedemikian mempunyai unsur mistik dan luar biasa serta rawatannya tidak dilakukan seperti mana rawatan yang normal. Dalam sesetengah keadaan, perawat itu berusaha untuk menunjukkan kelebihan dan kemampuannya dalam rawatan sehingga dirinya dipandang sebagai seorang yang hebat dan dipercayai.

\section{PANDANGAN KESELURUHAN TERHADAP KAEDAH RAWATAN JARAK JAUH}

Daripada perbincangan di atas, pengkaji lebih cenderung untuk menyatakan bahawa adalah lebih baik sekiranya tidak menggunakan kaedah rawatan jarak jauh dalam rawatan penyakit di atas beberapa alasan, iaitu:

Pertama: Mengelak daripada timbulnya fitnah dan dakwaan sumbang terhadap rawatan Islam. Hal ini kerana, apabila disebutkan rawatan atau pengubatan Islam, bermakna pendekatan dan kaedah 
rawatan yang menepati lunas-lunas syariah serta bertepatan dengan amalan Nabi SAW, para sahabat serta para ulama salaf. Nabi SAW sendiri tidak pernah membantu para sahabat berbuat demikian melainkan Baginda secara langsung merawat sahabat yang sakit atau Baginda memberi nasihat dengan menyatakan cara dan siapa yang patut dirujuk untuk merawat penyakit sedemikian.

Kedua: Dari sudut keberkesanan dalam memohon kesembuhan daripada Allah SWT, sepatutnya adalah melalui pertemuan secara langsung antara pesakit dan perawat. Ini bermakna, adalah lebih baik berlaku pertemuan secara langsung dan bersemuka bagi memastikan tidak berlaku salah faham dalam pendekatan rawatan yang dilakukan. Walaupun demikian, tidak dinafikan bahawa kesembuhan itu milik Allah SWT dan bagaimana serta cara untuk berikhtiar mencari penawar itu adalah bergantung kepada usaha manusia itu sendiri tetapi masih perlu berpandukan syariat.

Ketiga: Sekiranya menggunakan kaedah rawatan jarak jauh dengan perawat mendakwa bahawa ada seseorang yang akan datang menjalankan rawatan ketika pesakit sedang tidur, maka pendekatan sedemikian adalah menyerupai amalan perbomohan dan ia adalah diharamkan. Ini bermakna perawat tersebut telah menggunakan pertolongan jin atau makhluk halus dalam rawatan yang dijalankan. Allah SWT telah jelas menyatakan bahawa memohon pertolongan jin atau makhluk halus itu tidak lain melainkan menambahkan lagi kesesatan dan jauh dari pertolongan Allah. Firman Allah SWT dalam ayat 6 surah al-Jin, maksudnya:

"Dan bahawa sesungguhnya adalah (amat salah perbuatan) beberapa orang dari manusia, menjaga dan melindungi dirinya dengan meminta pertolongan kepada ketua-ketua golongan jin, kerana dengan permintaan itu mereka menjadikan golongan jin bertambah sombong dan jahat."

Keempat: Pertemuan antara pesakit dengan perawat mewujudkan hubungan antara dua insan iaitu hubungan antara pesakit yang memerlukan bantuan dan pertolongan dengan perawat yang berusaha untuk menghulurkan bantuan dan samasama memohon kesembuhan daripada Allah SWT. Pada masa yang sama menghubungkan silaturrahim antara meraka. Hal ini bertepatan dengan penjelasan al-Quran yang menyebutkan bahawa 
setiap orang Islam itu adalah bersaudara dan mereka saling tolong menolong pada kebaikan. ${ }^{20}$

Walaupun demikian, pengkaji melihat bahawa tidak salah untuk menggunakan rawatan jarak jauh yang dilaksanakan melalui beberapa pendekatan berikut:

Pertama: Pengkaji sangat bersetuju jika perawat mengambil pendekatan dengan melakukan solat hajat bersama dengan ahli keluarga pesakit, mendoakan pesakit dari jarak jauh tanpa pengetahuan pesakit atau meminta ahli keluarga sama-sama mendoakan pesakit tanpa pengetahuan pesakit agar pesakit itu disembuhkan oleh Allah. Pendekatan ini bertepatan dengan saranan Nabi SAW dan ia mudah untuk mendapat kemakbulan doa tersebut daripada Allah SWT seperti mana disebutkan dalam hadis sebelum ini.

Kedua: Perawat sentiasa memastikan bahawa kaedah rawatan tersebut tidak menyalahi syariat Islam, tiada unsur keraguan hukum, tidak berunsurkan mistik atau menunjukkan sesuatu keajaiban, dan menggunakan ruqyah al-shar iyyah serta tidak menggunakan bahan-bahan rawatan yang diharamkan atau berunsurkan najis.

Ketiga: Rawatan yang dijalankan berlaku secara sedar dan berlaku komunikasi dua hala antara perawat dan pesakit jika menggunakan alatan perhubungan seperti telefon atau menggunakan internet. Kemudian, perawat melakukan rawatan menggunakan ruqyah al-shar'iyyah yang dibenarkan bukan menggunakan jampi atau mantera yang dilarang. Sebolehnya perawat mendapatkan bantuan ahli keluarga pesakit untuk membantu ketika proses rawatan tersebut.

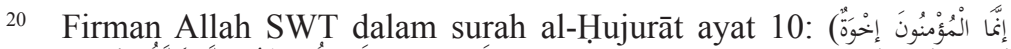

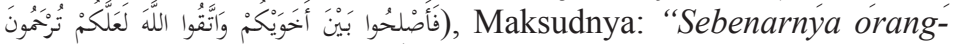
orang yang beriman itu adálah bersaudara, maka damaikanlah di antara dua saudara kamu (yang bertelingkah) itu; dan bertaqwalah kepada Allah supaya kamu beroleh rahmat”. Dan firman Allah SWT

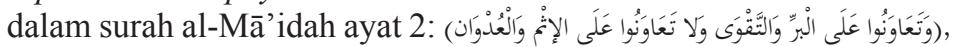
Maksudnya: "Dan hendaklah' kamú bertolong-tolongan untuk membuat kebajikan dan bertaqwa, dan janganlah kamu bertolongtolongan pada melakukan dosa (maksiat) dan pencerobohan." 


\section{KESIMPULAN}

Berdasarkan kepada perbincangan yang telah dikemukakan, dapat disimpulkan bahawa kaedah rawatan jarak jauh dari sudut hukumnya adalah berbeza mengikut situasi dan pendekatan perawat ketika rawatan itu dijalankan. Sekiranya perawat menggunakan pendekatan solat hajat, berdoa, menggunakan gambar pesakit atau melalui nama pesakit maka ianya dibenarkan selagi mana syariat Islam dijadikan sebagai landasan utama. Sebaliknya, sekiranya rawatan jarak jauh tersebut melibatkan unsur-unsur mistik atau boleh menimbulkan keraguan atau perawat melakukan perkaraperkara yang dilihat luar biasa maka rawatan seumpama ini sewajarnya dihindari. Ini adalah kerana amat ditakuti seandainya perawat tersebut mendapatkan pertolongan jin atau makhluk halus dalam rawatan yang dijalankan. Justeru, rawatan sedemikian sebaiknya dihindari oleh umat Islam kerana menggunakan khidmat dan bantuan jin dalam rawatan bukanlah sebahagian daripada rawatan Islam seperti mana yang dapat difahami daripada firman Allah di dalam ayat 6 surah al-Jin. Oleh yang demikian, kepada semua para pesakit yang sedang berusaha mencari kesembuhan, perkara utama yang perlu dititik beratkan adalah memastikan bahawa kaedah rawatan yang dijalankan oleh pusat rawatan Islam yang dikunjungi adalah tidak meragukan dan mengikut lunaslunas syariat Islam. Demikian juga bagi para perawat, mereka sewajarnya tidak memandang enteng dalam isu yang dibincangkan ini dan perlu komited dalam menyediakan khidmat rawatan Islam yang sejajar dengan syariat Islam. 
Jurnal Fiqh, No. 8 (2011) 65-80 